\title{
VIAJE SIN RETORNO: AVANCES Y DESAFÍOS EN LA PROTECCIÓN DE EXTRANJEROS BAJO LA CONDICIÓN DE REFUGIADOS $Y$ SOLICITANTES DE REFUGIO EN EL PERÚ
}

\author{
ONE WAY TRIP: ADVANCES AND CHALLENGES IN THE PROTECTION \\ OF FOREIGNERS UNDER REFUGEES STATUS AND REFUGEES \\ CLAIMANTS IN PERÚ
}

Karen Maribel Rebaza Vilchez ${ }^{1}$
Diana Carolina Guerra Bazán ${ }^{2}$

\section{Resumen}

El artículo presenta un breve análisis - desde una perspectiva en derechos humanos- de las obligaciones internacionales que tiene el Estado peruano frente a la afluencia de extranjeros en búsqueda del reconocimiento de la condición de refugiados y los que ya ostentan dicho estatus jurídico internacional.

Palabras Clave: Refugiados, solicitantes de refugio, derecho constitucional, Alto Comisionado de las Naciones Unidas para los Refugiados (ACNUR), instrumentos internacional de derechos humanos, medios de vida sostenibles.

\begin{abstract}
The article presents a summary analysis - from a human rights perspective - of the international obligations of the Peruvian State against the attendance of foreigners in search of the refugee recognition and those who already hold this international legal status.

Keys Words: Refugees, refugee claimants, constitutional rights, United Nations High Commissioner for Refugees (UNHCR), International instruments of human rights, sustainable livelihoods.
\end{abstract}

Abogada por la Universidad Femenina del Sagrado Corazón (UNIFÉ), especialista en Derecho Internacional Público, Derecho Constitucional y Derechos Humanos. Docente de la Facultad de Derecho de la misma casa de estudios. 2 Estudiante del IV ciclo de la Facultad de Derecho de la Universidad Femenina del Sagrado Corazón (UNIFÉ). 


\section{INTRODUCCIÓN}

El refugio entendido como la protección que encuentra una persona objeto de persecución fuera de su país de origen surgió como respuesta a la huida forzada de hombres, mujeres y niños luego de la Primera y Segunda Guerra Mundial, sin embargo, dicho estatus jurídico sigue siendo reconocido en diferentes países del mundo debido a los conflictos armados internos e internacionales de los que actualmente somos espectadores, como es el caso de Siria, Yemen, Iraq, entre otros.

Al mes de marzo de 2016, según estadísticas del Alto Comisionado de las Naciones Unidas para los Refugiados (ACNUR) el conflicto sirio ha producido más de cuatro millones de desplazados, en su mayoría reubicados en Egipto, Líbano y Jordania. Lamentablemente, la capacidad de acogida de estos países vecinos se ha visto sobrepasada y aproximadamente medio millón de sirios han llegado a Europa. Ante este arribo la Unión Europea se encuentra actualmente discutiendo la forma de ubicarlos entre sus Estados parte.

Por otro lado, países sudamericanos como Argentina, Brasil, Ecuador, Uruguay y Perú han empezado a entender esta crisis humanitaria y optar por regular programas de acogida para personas refugiadas, especialmente de nacionalidad siria.

Al respecto, a sorpresa de muchos medios de comunicación, el 11 de setiembre de 2015 el Ministerio de Relaciones Exteriores del Perú mediante Nota de Prensa oficial informó que nuestro país tiene actualmente más de 1800 personas de diferentes partes del mundo amparadas bajo la protección del refugio. Asimismo, anunció que frente a la crisis humanitaria provocada por el conflicto armado en Siria el Estado peruano asume el compromiso de agilizar los procedimientos en el reconocimiento de la condición de refugiado. Como se puede apreciar, la protección internacional que brinda dicho estatuto está sujeto a la discrecionalidad del Estado pero este se encuentra limitado frente a los compromisos que ha asumido frente a la comunidad internacional.

Dentro este orden de ideas, a continuación desarrollaremos en el presente artículo los puntos más relevantes del tema en cuestión. 


\section{TRATAMIENTO INTERNACIONAL DE LA FIGURA DEL REFUGIO}

El refugiado (a) según el artículo $1^{\circ}$ de la Convención sobre el Estatuto de los Refugiados de 1951 (Convención de Ginebra), modificada por el Protocolo sobre el Estatuto de los Refugiados de $1967^{3}$, es aquella persona que:

“(...)debido a fundados temores de ser perseguida por motivos de raza, religión, nacionalidad, pertenencia a determinado grupo social u opiniones políticas, se encuentre fuera del país de su nacionalidad y no pueda o, a causa de dichos temores, no quiera acogerse a la protección de tal país; o que, careciendo de nacionalidad y hallándose, a consecuencia de tales acontecimientos, fuera del país donde antes tuviera su residencia habitual, no pueda o, a causa de dichos temores, no quiera regresar a él." (Convención de Ginebra, 1951)

Asimismo, la Declaración de Cartagena de 1984, instrumento de protección complementaria amplia la definición de refugiados, reconoce como tales aquellas personas que:

"han huido de su país de origen para salvaguardar su seguridad, integridad física y vida a causa de la violencia generalizada, violación masiva de los derechos humanos $u$ otras circunstancias que hayan perturbado gravemente el orden público." (Declaración de Cartagena, 1984)

Si bien la Declaración no es vinculante por pertenecer al soft law del Derecho Internacional, nuestro país ha optado por incluir esta definición ampliada del concepto de refugiado en su legislación interna, tal y como veremos más adelante al revisar con detenimiento el marco jurídico peruano.

Ahora bien, a partir de la Convención de Ginebra, se destaca el llamado al respeto y/o garantía que debe brindar el Estado frente a los siguientes derechos:

- El suministro de un documento de identidad y un documento de viaje (artículos $27^{\circ}$ y $28^{\circ}$ );

- El derecho al trabajo (artículo $17^{\circ}, 18^{\circ}$ y $19^{\circ}$ );

- El acceso libre a los tribunales (artículo $16^{\circ}$ );

El Protocolo de 1967 es un instrumento independiente de la Convención. Su aporte fundamental es que anula los límites geográficos y temporales contenidos en la Convención de Ginebra. En efecto, la Convención limitaba el reconocimiento de la condición de refugiado a las personas que se encontraban fuera de su país de origen debido a acontecimientos ocurridos antes del 01 de enero de 1951 y así se limitaba la posibilidad de que los Estados tomen en cuenta nuevas situaciones de refugio. 
- La asistencia para cubrir sus necesidades físicas y materiales (artículo $\left.23^{\circ}\right)$;

- La libertad de movimiento (artículo $26^{\circ}$ );

- El derecho a la educación por lo menos primaria (artículo $22^{\circ}$ ).

Por otro lado, se desprenden de dicha Convención tres principios fundamentales en materia de protección internacional de las personas refugiadas a detallarse a continuación:

\begin{tabular}{|c|c|c|}
\hline $\begin{array}{l}\text { No Devolución (artí- } \\
\text { culo } 33^{\circ} \text { ) }\end{array}$ & $\begin{array}{l}\text { No sanción por ingreso } \\
\left.\text { irregular (artículo } 31^{\circ}\right)\end{array}$ & 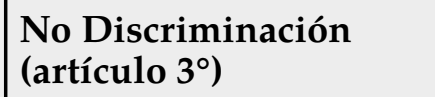 \\
\hline $\begin{array}{l}\text { Este Principio esta- } \\
\text { blece la obligación } \\
\text { que tiene un Estado } \\
\text { de no enviar a una } \\
\text { persona refugiada a } \\
\text { un territorio donde } \\
\text { pueda existir peligro } \\
\text { para su vida. }\end{array}$ & $\begin{array}{l}\text { Este Principio indica que } \\
\text { el ingreso sin previa au- } \\
\text { torización no debe ser } \\
\text { sancionado para garanti- } \\
\text { zar el acceso a la condi- } \\
\text { ción de refugiado. }\end{array}$ & $\begin{array}{l}\text { Este Principio dispone } \\
\text { que las disposiciones de } \\
\text { la Convención se apli- } \\
\text { quen sin discriminación } \\
\text { por motivos de raza, re- } \\
\text { ligión o país de origen. }\end{array}$ \\
\hline
\end{tabular}

Respecto al Principio de "No Discriminación" resulta importante añadir que éste está previsto en el Derecho Internacional de los Derechos Humanos con una lista mucho más amplia de motivos prohibidos. En ese sentido, la discriminación se debería entender como $^{5}$ :

"toda distinción, exclusión, restricción o preferencia que se basen en determinados motivos, como la raza, el color, el sexo, el idioma, la religión, la opinión política o de otra índole, el origen nacional o social, la posición económica, el nacimiento de cualquier otra condición, y que tengan por objeto o por resultado anular o menoscabar el reconocimiento, goce o ejercicio, en condiciones de igualdad, de los derechos humanos y libertades fundamentales de todas las personas" (Comité de Derechos Humanos, 1989).

Ahora bien, es importante recordar que el reconocimiento de la condición de refugiado tiene carácter declarativo, por tanto, la decisión del Estado sólo reconoce y confirma formalmente que un individuo es una persona refugiada.

Este derecho se recoge también en el artículo $5^{\circ}$ del Protocolo contra el Tráfico Ilícito de Migrantes por Tierra, Mar y Aire. Cfr. Asamblea General de la ONU 2000.

Comité de Derechos Humanos. Observación General 18, No discriminación. Organización de las Naciones Unidas, 10/11/89, CCPR/C/37, párr. 7 . 
Como consecuencia, a partir de que un extranjero expresa su necesidad de buscar dicho reconocimiento se aplica automáticamente el principio de No Devolución ${ }^{6}$. Mientras el Estado define si reconoce formalmente esta condición, la persona es denominada "solicitante de refugio" y ya cuenta con protección internacional.

Cuando un extranjero solicita refugio su procedimiento se desarrolla en dos etapas: la primera consiste en comprobar los hechos del caso; y la segunda, en el análisis de lo relatado a la luz de los instrumentos internacionales descritos y legislación interna en la materia. Al respecto, el Alto Comisionado de las Naciones Unidas (ACNUR) ha considerado como necesarias el seguimiento de las siguientes pautas ${ }^{7}$

- Procedimiento especializado para las solicitudes de refugio.

- Autoridad claramente identificada y especializada en materia de refugio; $y$,

- Acceso físico a la determinación del estatuto de refugiado.

Otra garantía importante es el derecho a la representación legal, respecto al cual la Comisión Interamericana de Derechos Humanos ha precisado que en el marco de la presentación de las solicitudes de refugio:

- La representación por un abogado competente resulta del interés del refugiado tomando en cuenta la naturaleza del proceso de determinación (proceso complicado y usualmente desconocido por parte del refugiado) y los intereses en juego (el reconocimiento de la condición de refugiado y los derechos que abarca el mismo).

- La representación legal es necesaria en la medida en la cual garantice que el recurso sea ejercido de manera efectiva ${ }^{8}$.

Por otro lado, es preciso apuntar los estándares desarrollados por el ACNUR en relación a los solicitantes de refugio. Respecto a ellos se ha previsto:

- El derecho a un documento de identidad que sea válido hasta que se defina su situación;

Alto Comisionado de las Naciones Unidas para los Refugiados. Opinión Consultiva sobre la aplicación extraterritorial de las obligaciones de no devolución en virtud de la Convención sobre el Estatuto de los Refugiados de 1951 y su Protocolo de 1967.

7 Observaciones del ACNUR acerca de la propuesta de la Comisión Europea de una Directiva del Consejo sobre normas mínimas para los procedimientos de concesión o retirada del estatuto de refugiado, 2000

8 Para mayor información: http://www.acnur.org/fileadmin/Documentos/Proteccion/Buenas_Practicas/9209.pdf?view=1 Consultado el 01 de agosto de 2016 
- El acceso a las necesidades básicas como alojamiento, alimentación, vestimenta y acceso a la salud';

- El derecho a residir temporalmente en el país de destino ${ }^{10}$.

La legislación internacional citada establece para el Estado peruano una obligación de resultado que se enuncia en el pacta sunt servanda ("lo pactado obliga") y en materia de derechos humanos esta resulta esencial.

De acuerdo con el artículo $1^{\circ}$ inciso 1 de la Convención Americana sobre Derechos Humanos, el Estado tiene la obligación de respetar los derechos fundamentales y de garantizar su libre y pleno ejercicio a toda persona que esté sujeta a su jurisdicción, sin discriminación alguna, es decir, sin importar su estatus migratorio. Los solicitantes de la condición de refugiado y refugiados en el Perú han visto vulnerada su dignidad humana en su país de origen al no garantizárseles el derecho a tener un buen desarrollo, a la libertad, a la paz, a la tranquilidad y a la vida, al recibir daños contra su integridad física, moral y psicológica; ello no se puede repetir en el país de acogida.

Por otro lado, la Convención Americana de Derechos Humanos de 1969, en sus artículos 22.7 y 22.8 , señalan lo siguiente:

"22.7. Toda persona tiene el derecho de buscar y recibir asilo en territorio extranjero en caso de persecución por delitos políticos o comunes conexos con los políticos y de acuerdo con la legislación de cada Estado y los convenios internacionales. (el subrayado es nuestro).

22.8. En ningún caso el extranjero puede ser expulsado o devuelto a otro país, sea o no de origen, donde su derecho a la vida o a la libertad personal está en riesgo de violación a causa de raza, nacionalidad, religión, condición social o de sus opiniones politicas". (Convención Americana de Derechos Humanos, 1969)(el subrayado es nuestro).

Como se puede observar, a través de dichos dispositivos normativos, el respeto por los derechos de los refugiados y solicitantes de refugio se hace justiciable ante la Corte Interamericana de Derechos Humanos.

Para mayor información: http://www.refworld.org/pdfid/4b0d4b5c2.pdf Consultado el 01 de agosto de 2016.

10 Para mayor información: http://www.acnur.org/t3/fileadmin/Documentos/BDL/2010/8014.pdf?view=1 Consultado el 01 de agosto de 2016 
En ese sentido, consideramos oportuno hacer referencia a la sentencia del caso Pacheco Tineo, de fecha 25 de noviembre de 2013 ${ }^{11}$, donde el Estado Plurinacional de Bolivia fue encontrada responsable por la violación del derecho a buscar y recibir refugio, del principio de no devolución (contenidos en el derecho de circulación y residencia) y de los derechos a las garantías judiciales y a la protección judicial, reconocidos en los artículos 22.7, 22.8, 8 y 25 de la Convención Americana. Así como por la violación del derecho a la protección de los niños y de la familia, reconocidos en los artículos $19^{\circ} \mathrm{y}$ $17^{\circ}$ de la Convención Americana, en relación con los artículos 8.1, 22.7, 22.8, $25^{\circ}$ y 1.1 de la misma.

En la citada Sentencia, la Corte plantea las siguientes garantías de obligatorio cumplimiento para los Estados parte:

- Un procedimiento especializado para las solicitudes de refugio con autoridad claramente identificada y especializada en materia de refugio.

- El derecho a la información del solicitante de refugio sobre el procedimiento y las posibilidades de recurrir la decisión.

- $\quad$ El derecho decisiones fundamentadas o motivadas.

- La protección de datos y principio de confidencialidad.

- $\quad$ El acceso a traductores, asistencia jurídica y representación legal.

En relación especialmente al derecho a la representación legal, la Comisión Interamericana de Derechos Humanos ha precisado que en el marco de la presentación de las solicitudes de refugio: la representación por un abogado competente resulta del interés del refugiado tomando en cuenta la naturaleza del proceso de determinación (proceso complicado y usualmente desconocido por parte del refugiado) y los intereses en juego (el reconocimiento de la condición de refugiado y los derechos que abarca el mismo), es decir, la representación legal es necesaria en la medida en la cual garantice que el recurso sea ejercido de manera efectiva ${ }^{12}$.

\section{EL ESTATUTO DE REFUGIADO EN LA LEGISLACIÓN NACIONAL}

\subsection{Constitución Política del Perú}

La Constitución no hace mención a la protección de refugiados, pero sí al asilo político en su artículo $36^{\circ}$ el cual tiene una regulación distinta al

BDL/2013/9390.pdf?view=1. Consultado el 1 de agosto de 2016.

12 Para mayor información: http://www.acnur.org/t3/fileadmin/Documentos/BDL/2013/9390.pdf?view=1. Consultado el 1 de agosto de 2016. 
marco legal de refugiado en el Perú. Al respecto, es importante indicar que pese a que no exista una protección expresa constitucional a los refugiados, ello no impide la declaración de responsabilidad del Estado peruano frente a esta población vulnerable. Vale recordar que la Cuarta Disposición Final y Transitoria de nuestra Constitución señala que:

"Las normas relativas a los derechos y a las libertades que la Constitución reconoce se interpretan de conformidad con la Declaración Universal de Derechos Humanos y con los tratados y acuerdos internacionales sobre las mismas materias ratificados por el Perú". (Constitución Política del Perú, 1993)

Asimismo, al respecto el Tribunal Constitucional peruano señala que ${ }^{13}$ :

"La constitución... exige a los poderes públicos nacionales que, a partir del ejercicio hermenéutico, incorporen en el contenido protegido de los derechos constitucionales los ámbitos normativos de los derechos humanos reconocidos en los referidos tratados. Se trata de un reconocimiento implícito de la identidad nuclear sustancial compartida por el constitucionalismo y el sistema internacional de protección de los derechos humanos: la convicción jurídica del valor de la dignidad de la persona humana, a cuya protección y servicio se reconduce, en última y definitiva instancia el ejercicio de todo poder". (Tribunal Constitucional del Perú, 2006)

\subsection{Ley del Refugiado (Ley $\mathrm{N}^{\circ}$ 27891) y su Reglamento (Decreto Supremo No119-2003-RE}

Desde el año 2002, el Perú reconoce formalmente la condición de refugiado a través de la promulgación de la Ley N 27891 y de su Reglamento aprobado por Decreto Supremo N 119-2003-RE en el 2003.

Dicha normas jurídicas se rigen por los lineamientos establecidos en la Convención sobre el Estatuto de los Refugiados de 1951 y el Protocolo sobre el Estatuto de Refugiados de 1967, estableciendo las condiciones, procedimientos y organismos encargados de la determinación de la condición de refugiados en la República del Perú. Así como también establecen los derechos y obligaciones de los refugiados y solicitantes de refugio.

La Ley de Refugiados en su artículo $3^{\circ}$ define a la persona refugiada como:

13 Sentencia $N^{\circ}$ 02730-2006-PA/TC, párrafo 9. 
“a) A la persona que debido a fundados temores de ser perseguida por motivos de raza, religión, nacionalidad, pertenencia a un determinado grupo social $u$ opiniones políticas, se encuentre fuera del país de su nacionalidad y no pueda o, a causa de dichos temores, no quiera acogerse a la protección de tal país; o que careciendo de nacionalidad y hallándose, a consecuencia de tales acontecimientos, fuera del país donde antes tuviera su residencia habitual, no pueda o, a causa de dichos temores, no quiera regresar a él.

b) A la persona que se ha visto obligada a huir de su país de nacionalidad o de residencia habitual por causa de la violación masiva de los derechos humanos, agresión extranjera, conflicto interno, ocupación o dominación extranjera; o en razón de acontecimientos que perturben gravemente el orden público.

c) A la persona que encontrándose legalmente en el territorio de la República, debido a causas sobrevinientes surgidas en su país de nacionalidad o de residencia, no puede o no quiere volver a dicho país debido al temor de sufrir persecución de acuerdo al inciso a) del presente artículo." (Ley del Refugiado, 2002)

Como se puede observar, la Ley peruana reconoce al refugiado de acuerdo a la definición de la Convención sobre el Estatuto de refugiado, a la Declaración de Cartagena y finalmente prevé la figura del refugiado sur place ${ }^{80}$. Asimismo, la Ley y el Reglamento reconocen varios estándares establecidos por el derecho internacional de los refugiados:

- Derecho a la no devolución a un país en el cual la vida, integridad física o la libertad del que solicite refugio está amenazada (artículo $5^{\circ}$ de la Ley y $3^{\circ}$ del Reglamento).

- El principio de no sanción por ingreso o permanencia ilegal (artículo $31^{\circ}$ de la Ley y $3^{\circ}$ del Reglamento).

- El derecho a la unidad familiar con la posibilidad de extender la calidad de refugiado al cónyuge, pareja de hecho, hijos u otra persona dependiente a nivel económico del refugiado cuando es requerido y acreditado (artículo $25^{\circ}$ de la Ley y $3^{\circ}$ del Reglamento).

- La confidencialidad de la información de los casos (artículo $3^{\circ}$ del Reglamento).

- Contar con un traductor en caso de resultar necesario (artículo $23^{\circ}$ del Reglamento).

\footnotetext{
14 Es aquella persona que no tenía temores fundados de persecución al abandonar su país de nacionalidad, pero que adquiere posteriormente y de forma sobrevenida tal condición en virtud de circunstancias que surgieron en su país de origen durante su ausencia.
} 
De acuerdo al Capítulo IV del Reglamento de la Ley del Refugiado, se presentan las siguientes etapas:

Solicitud de Refugio: El procedimiento empieza por la solicitus de refugio la cual pede ser presentada en fronteras, puestos de control migratorio, reparticiones policiales o militares o ante la Comisión Especial. La solicitud tiene que ser escrita. Es importante precisar que las autoridades migratorias y las autoridades militares o piliciales deben permitir el ingreso del extranjero que solicte refugio y le deberán orientar sobre el procedimiento a seguir. Las autoridades deberán remitir formalmente a la Comisión Especial las solicituddes en un plazo no mayor a 15 días calendarios.

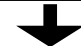

Entrevista: La segunda etapa será la entrevista al solicitante de refugio por el Secretario Ejecutivo de la Comisión Especial o su representante.

Decisión de la Comisión mediante Resolución: La Comisión Especial es el órgano que resolverá en primera instancia y en reconsideración la solicitud de reconocimiento de la condición de refugiado. El plazo para la decisión es de 60 días renovables cuantas veces sea necesario. La decisión debe constar en una resolución vinculante para los demás sectores del Estado.

Recurso de reconsideración: La decisión denegatoria fundamentada puede ser impugnada y para eso la persona solicitante, su representante legal o el ACNUR debe presentar un recurso de reconsideración en el plazo de los 15 días hábiles ante la Comisión Especial para los Refugiados. La Comisión tiene 30 días para resolverlo.

Recurso de apelación ante la Comisión Revisora para Asuntos de Refugiados: La Comisión Revisora es el órgano encargado de resolver en última y definitiva instancia, las apelaciones interpuestas contra las resoluciones emitidas por la Comisión Especial para los Refugiados. La persona solicitante, su representante legal o el ACNUR dispone de un plazo de 15 días de notificada la resolución para apelar. La Comisión Revisora tendrá un plazo de 30 días hábiles para resolver, prorrogables por igual plazo. Es importante subrayar que el Reglamento prevé que la decisión de la Comisión será definitiva.

Consecuencias del reconocimiento o de la denegación: Si la persona solicitante ha sido reconocida como refugiada se le otorgará la calidad migratoria de extranjero residente por un año prorrogable.

En caso que se haya denegado la solicitud de refugio, el solicitante se someterá a las normas de extranjería. El Reglamento precisa que de ser necesario se podrá otorgar un plazo de permanencia de tres meses al extranjero a quien se vio denegada su solicitud. 
Ahora bien, el artículo 6 de la Ley $N^{\circ}$ 27891, Ley del Refugiado, señala:

"El Ministerio de Relaciones Exteriores es el sector encargado de velar por el debido cumplimiento de las obligaciones y compromisos asumidos por el Estado en relación con el Derecho Internacional de los Refugiados, así como de las leyes internas sobre la materia".

Al respecto, el Reglamento de Organización y Funciones (ROF) del Ministerio de Relaciones Exteriores (MRE), en su artículo $99^{\circ}$ incisos k, 1 y m, expresa lo siguiente:

"Son funciones específicas de la Dirección Humanos (...) k) Gestionar y tramitar los pedidos individuales o colectivos del refugio en el Perú, coordinando con las autoridades nacionales competentes la aplicación de los Tratados Internacionales sobre refugio; l) Ejercer las funciones de la Presidencia de la Comisión Especial para los Refugiados y las funciones de la Secretaría Ejecutiva; y m) Llevar la documentación, registro y archivo de los casos de refugio y asilo en el Perú". (Reglamento de Organización y Funciones (ROF) del Ministerio de Relaciones Exteriores, 2010)

En ese sentido, la Dirección de Derechos Humanos del MRE es la oficina encargada de atender todos los temas relacionados con este grupo vulnerable, a través de la Comisión Especial para los Refugiados (CEPR).

La CEPR ${ }^{15}$, asume la responsabilidad de recibir, analizar y resolver en primera instancia las solicitudes de la condición de refugiado. Asimismo, de velar porque los distintos organismos del Estado, aseguren el cumplimiento de lo establecido en normativa nacional e internacional.

Ante estas consideraciones, nos permitimos desglosar la siguiente información brindada por la CEPR ${ }^{16}$ :

\footnotetext{
15 Está integrada por dos representantes del Ministerio de Relaciones Exteriores y uno del Ministerio del Interior. Así mismo, está integrada por el Secretario Ejecutivo de la Comisión, que es designado por su Presidente, y un representante del ACNUR, ambos con derecho a voz pero sin derecho a voto.

16 "Cartilla Informativa para refugiados y solicitantes de refugio". Recibida en sede del Ministerio de Relaciones Exteriores del Perú el 10 de junio de 2016.
} 


\begin{tabular}{|c|c|}
\hline \multicolumn{2}{|c|}{ Derechos reconocidos a los solicitantes de refugio y refugiados } \\
\hline $\begin{array}{c}\text { Libertad de } \\
\text { tránsito }\end{array}$ & $\begin{array}{l}\text { Los solicitantes de refugio acceden a un documento provisional } \\
\text { (carné de solicitante de refugio”) expedido por la secretaría de } \\
\text { la CEPR, el cual lo acredita como tal y le permite desplazarse en } \\
\text { territorio peruano. } \\
\text { Los extranjeros al ser reconocidos como refugiados acceden a un } \\
\text { Carné de Extranjería" expedido por las autoridades migratorias. }\end{array}$ \\
\hline A la educación & $\begin{array}{l}\text { Los solicitantes y refugiados pueden inscribirse en los centros de } \\
\text { estudio públicos y privados del país. }\end{array}$ \\
\hline Al trabajo & $\begin{array}{l}\text { Los solicitantes pueden ser contratados e ingresar a planilla. } \\
\text { Los dependencia pueden ser contratados o trabajar en relación } \\
\text { condiciones de empleo deberán ser conforme a la ley. En el Perú, } \\
\text { se sanciona la explotación laboral y sexual. }\end{array}$ \\
\hline \multicolumn{2}{|c|}{ Obligaciones de los solicitantes de refugio y refugiados } \\
\hline$\checkmark$ & Respetar las leyes nacionales, provinciales y/o municipales. \\
\hline$\checkmark$ & $\begin{array}{l}\text { Renovar el documento provisorio como solicitante o el Carné de Extran- } \\
\text { jería. }\end{array}$ \\
\hline$\checkmark$ & Informar a la Secretaria Ejecutiva sobre su intención de viajar al exterior. \\
\hline & $\begin{array}{l}\text { En el caso de las personas que ya han obtenido la condición de refugiados, } \\
\text { se tendrá que pedir permiso de viaje al presidente de la CEPR. }\end{array}$ \\
\hline$\checkmark$ & Informar su domicilio y mantenerlo actualizado. \\
\hline
\end{tabular}

\subsection{Decreto Legislativo $N^{\circ} 1236$, Nueva Ley de Extranjería}

El Decreto Legislativo $1236^{\circ}$, publicado en el diario el peruano el 25 de setiembre del 2015, regula el ingreso, permanencia, residencia, salida, reingreso y control de nacionales de otro país en el Perú. Asimismo, incorpora nuevas calidades migratorias, define plazos de permanencia y residencia para las mismas, y modifica lo referente al cambio de calidad migratoria de los nacionales de otro país admitidos en el territorio peruano. Sin embargo, es importante precisar que a la fecha la ley no cuenta con un reglamento, lo que genera una serie de dificultades en su implementación.

La Ley reconoce la calidad migratoria de refugiado definiéndola como un estatuto jurídico otorgado por el Estado peruano para la protección de sus 
titulares mediante la categoría migratoria temporal (artículo 53.2) y calidad migratoria humanitaria (artículo 59.2).

Además, resulta importante recalcar que esta Ley define la competencia del Ministerio de Relaciones Exteriores para otorgar tal calidad migratoria a los extranjeros que la soliciten y determinar la pérdida de la misma previa calificación y de conformidad con la Ley y con los convenios vigentes para la República.

\section{POLÍTICAS PÚBLICAS E INICIATIVAS DE LA SOCIEDAD CIVIL EN MATERIA DE INTEGRACIÓN DE REFUGIADOS Y SOLICITANTES DE LA CONDICIÓN DE REFUGIADOS}

\subsection{Medios de vida sostenibles}

Desde la perspectiva del ACNUR $^{17}$, los medios de vida sostenibles comprenden las capacidades, los recursos (humanos, naturales y de capital, financieros, físicos y sociales) y las actividades necesarias de los refugiados y solicitantes de tal condición para sostenerse y hacerle frente al estrés y las crisis producto de la huida de su país de origen.

Un medio de vida sostenible se compone de los siguientes atributos: capacidades humanas (como la educación, habilidades, salud y orientación psicológica); el acceso a activos tangibles e intangibles; y la existencia de actividades económicas.

\subsection{Trabajo en el sector público}

La CEPR, en representación del Estado peruano, viene realizando los esfuerzos necesarios para la garantía de los derechos económicos y sociales de las personas ya reconocidas como refugiados. En ese sentido, a continuación se presenta un cuadro resumen de los beneficios que ofrecen ciertas entidades del sector público en el Perú para esta población:

ACNUR. Programación del ACNUR sobre medios de vida sostenibles: Directrices Operativas. Ginebra, Suiza; 2010, pág.147. 


\begin{tabular}{|c|c|c|c|}
\hline \multicolumn{2}{|c|}{ SECTOR } & BENEFICIO & NORMATIVIDAD \\
\hline $\begin{array}{l}\text { Economía y } \\
\text { Finanzas }\end{array}$ & $\begin{array}{l}\text { Superintenden- } \\
\text { cia Nacional de } \\
\text { Aduanas y de Ad- } \\
\text { ministración Tri- } \\
\text { butaria (SUNAT) }\end{array}$ & $\begin{array}{l}\text { - Obtención del RUC } \\
\text { (Registro Único del } \\
\text { Contribuyente) para } \\
\text { solicitantes de refu- } \\
\text { gio }\end{array}$ & $\begin{array}{l}\text { Oficio N } N^{\circ} 511-2000- \\
\text { SUNAT } / 200000\end{array}$ \\
\hline Salud & $\begin{array}{l}\text { SIS (Sistema In- } \\
\text { tegral de Salud); } \\
\text { Organismo Públi- } \\
\text { co Ejecutor (OPE) } \\
\text { del MINSA }\end{array}$ & $\begin{array}{l}\text { - Afiliación al Régi- } \\
\text { men de Financia- } \\
\text { miento y Subsidiado } \\
\text { del Sistema Integral } \\
\text { de Salud }\end{array}$ & $\begin{array}{l}\text { Directiva } \\
\mathrm{N}^{\circ} 001-2012-\mathrm{SIS}\end{array}$ \\
\hline $\begin{array}{l}\text { Transporte y } \\
\text { Comunica- } \\
\text { ciones }\end{array}$ & $\begin{array}{l}\text { Ministerio de } \\
\text { Transporte }\end{array}$ & $\begin{array}{l}\text {.Licencia de conducir } \\
\text { para extranjeros y so- } \\
\text { licitantes de refugio } \\
\text { y refugiados (as); en } \\
\text { clase A, categorías I, } \\
\text { II-a, II-b y III-a, III-b } \\
\text { o III-c } \\
\text {. Aprobación del For- } \\
\text { mato de licencia de } \\
\text { conducir provisional } \\
\text { para extranjeros que } \\
\text { solicitan refugio o } \\
\text { asilo }\end{array}$ & $\begin{array}{l}\text { Decreto Supremo } \\
\text { № 040-2008-MTC } \\
\text { Resolución Directoral № } \\
\text { 1054-2011-MTC/15 }\end{array}$ \\
\hline
\end{tabular}

Cabe mencionar que se encuentra en proceso de evaluación, la solicitud de parte de la CEPR, de la revalidación de títulos de los ciudadanos extranjeros en condición de refugiados ante la Superintendencia Nacional de Educación Superior Universitaria (SUNEDU) ${ }^{18}$.

\subsection{Trabajo desde la sociedad civil}

Si bien lo avanzado por el sector púbico es importante para la integración de los refugiados, es menester trabajar con la sociedad civil. Ante ello, bajo el apoyo de ENCUENTROS-Servicio Jesuita para la Solidaridad, como Agencia Implementadora de los Programas del ACNUR y socio aliado-estratégico estatal, se brinda apoyo humanitario no solo a los refugiados sino también a los solicitantes de refugio de manera temporal y dentro de sus posibilidades reales $^{19}$. 
Siendo el objetivo a corto plazo de ENCUENTROS asistir humanitariamente a esta población vulnerable, a mediano y largo plazo tiene como objetivo lograr la autosuficiencia de los mismos, desde el desarrollo u optimización de sus fortalezas, capacidades, habilidades y destrezas, de modo tal que en una primera instancia se apliquen los beneficios de las Personas en Necesidad de Protección Internacional ${ }^{20}$ (PNPI), en el entorno público, privado o de la sociedad civil; $y$, en una segunda instancia, puedan logar su autodeterminación atendiendo sus principales necesidades básicas y complementarias.

Por tanto, para el ACNUR la asistencia humanitaria no constituye un derecho inherente a la condición de refugiado o solicitante de refugio, sino un mecanismo de protección, aplicable hasta su autodeterminación o auto asistencia.

En cuanto a la población beneficiaria, los grupos focales son:

Solicitantes de Refugio.

Refugiados (as) reconocidos por la CEPR.

Siendo la población preferente o prioritaria:

Menores no acompañados o separados.

Mujeres embarazadas.

Víctimas de tortura, violencia sexual y basada en género.

Adultos mayores sin apoyo familiar.

Personas con discapacidades físicas, mentales y/o emocionales que los / las incapacitan para trabajar temporal o permanentemente.

Familias monoparentales con hijos menores dependientes que impiden el trabajo del jefe de familia.

Familias extensas con hijos menores y sin recursos económicos.

Por otro lado, es importante señalar que, según la información recabada, a la fecha de la presente publicación en el sector privado no se han presentado iniciativas concretas que tengan el objetivo de velar por la reintegración de esta población.

Personas en necesidad de protección internacional (PNPI): categoría que agrupa a la población de interés del ACNUR: refugiados, solicitantes de refugio, desplazados internos, apátridas y retornados. Información estadística actualizada en: http://www.acnur.org/t3/donde-trabaja/america/ 


\section{CONCLUSIONES}

La Comisión Especial para los Refugiados está realizando los esfuerzos necesarios para que los refugiados y solicitantes de dicha condición tengan la posibilidad de goce y disfrute de sus derechos humanos. Sin embargo, el esfuerzo realizado por esta Comisión es estéril si no trae consigo la colaboración estatal y privada mediante políticas concretas a la altura de los estándares internacionales que se vienen construyendo en la región.

Asimismo, consideramos que se hace necesario diseñar y aplicar mecanismos de difusión del carnet de solicitante de refugio (a) y / o refugiado (a), a través de Campañas y Recursos de comunicación (físicos y/o virtuales), donde se resalten historias de vida (o de éxito), que den cuenta de los logros de los extranjeros refugiados en el Perú que sirvan de modelo de vida a otros, y así se contribuya a la buena imagen de esta población vulnerable.

El reto está en velar por el acceso a la satisfacción de necesidades básicas mediante la unión de políticas públicas con la iniciativa privada. Bajo nuestra opinión, creemos que ello sería posible a través de la promoción de gestiones intersectoriales en base a la integración de refugiados y solicitantes de refugio a los beneficios de los distintos Programas Sociales (con énfasis en vivienda, alimentación/nutrición, educación y salud).

Muchos refugiados en el Perú aseguran que por el contexto que han vivido en su país de origen han tomado un viaje sin retorno. Hagamos que el paso o permanencia de esta población sea más llevadera recordando que el respeto por los derechos humanos no necesita bandera.

\section{REFERENCIAS}

Nash Rojas, Claudio (2011). Relación entre el sistema constitucional e internacional de los derechos humanos". En Revista sobre cultura, democracia y derechos humanos del Instituto de Derechos Humanos de la PUCP.

Alto Comisionado de las Naciones Unidas para los Refugiados (ACNUR). Acuerdo Marco para Reasentamiento de Refugiados con el Alto Comisionado de las Naciones Unidas para los Refugiados. Disponible en Internet: http://www. acnur.org/fileadmin/Documentos/Proteccion/Buenas_Practicas/9209. pdf?view=1. Consultado el 12 de mayo de 2016.

Alto Comisionado de las Naciones Unidas para los Refugiados (ACNUR). Identificación de las necesidades alimentarias y no Alimentarias de los desplazados. 
Disponible en Internet: http://www.refworld.org/pdfid/4b0d4b5c2.pdf. Consultado el 05 de junio de 2016.

Alto Comisionado de las Naciones Unidas para los Refugiados (ACNUR). El asilo en los instrumentos internacionales y las constituciones políticas iberoamericanas.

Disponible en Internet: http: / / www.acnur.org/t3/fileadmin/Documentos/ BDL/2010/8014.pdf?view=1. Consultado el 19 de abril de 2016.

Corte Interamericana de Derechos Humanos. Sentencia del caso "Pacheco Tineo vs. Estado Plurinacional de Bolivia", emitida el 25 de noviembre de 2013.

Alto Comisionado de las Naciones Unidas para los Refugiados (ACNUR). Programación del ACNUR sobre medios de vida sostenibles: Directrices Operativas. Disponible en Internet: http://www.acnur.es/PDF/Programacion_ ACNUR_medios_sostenibles.pdf. Consultado el 10 de abril de 2016.

Tribunal Constitucional peruano. Sentencia $N^{\circ}$ 02730-2006-PA/TC, publicada el 27 de julio de 2006 en el portal oficial del Tribunal Constitucional; párrafo 9.

"Cartilla Informativa para refugiados y solicitantes de refugio". Obtenido en las instalaciones del Ministerio de Relaciones Exteriores del Perú.

Fecha de recepción : 31 de agosto de 2016

Fecha de aceptación : 22 de setiembre de 2016 
